\title{
LIBERTAD Y CONSENTIMIENTO EN EL PENSAMIENTO POLÍTICO DE JOHN LOCKE
}

\author{
Óscar Godoy Arcaya \\ Instituto de Ciencia Política, Pontificia Universidad Católica de Chile
}

\begin{abstract}
Resumen
El autor estudia el pensamiento político maduro de John Locke, contenido especialmente en el Segundo Tratado de Gobierno, para rastrear dos claves de su concepción sobre el origen del Estado y de los regímenes políticos. Estas claves son la libertad y el consentimiento. Locke sostiene la libertad natural de la persona como el fundamento de la sociedad políticamente organizada. La tesis que el autor expone argumenta que esa libertad se expresa como pacto o contrato para instituir la sociedad política o Estado y como decisión mayoritaria para adoptar un régimen político o de gobierno. A la luz de estas dos modalidades de consentimiento, el autor analiza sus efectos en la sociedad política y el régimen político.

Abstract

The author studies the mature political thought of John Locke, contained especially in the Second Treatise of Government, in order to track two key concepts in his views on the origin of the State and political regimes. These two concepts are freedom and consent. Locke argues that the natural freedom of the person constitutes the foundation of politically organized society. The author's thesis is that that freedom is expressed as a pact or contract to institute a political society or State, and as a majoritarian decision to adopt a political regime or government. In light of these two modes of consent, the author analyzes their effects on political society and the political regime.
\end{abstract}

\section{PALABRAS CLAVE • John Locke • Libertad • Consentimiento • Teoría Política Moderna}

Dos obras fundamentales del pensamiento político de John Locke -Dos Tratados del Gobierno y Carta sobre la Tolerancia- aparecen en 1689. Un año después sale a la luz pública su obra filosófica capital, el célebre Ensayo sobre el Entendimiento Humano (1690). Así, en un espacio muy breve de tiempo, se publica el resultado de un largo proceso de elaboración de su pensamiento político y filosófico, cuyos comienzos se remontan a los años sesenta del siglo XVII. Este ensayo analiza el Segundo Tratado del Gobierno, que Locke concibió como la segunda parte de los Dos Tratados del Gobierno, escrito donde se concentra el núcleo fundamental y maduro del pensamiento político de Locke $^{1}$. El propósito de este artículo es examinar dos hilos conductores

* Una versión preliminar de este artículo fue presentada en el VII Congreso de la Asociación Chilena de Ciencia Política, el 26 de agosto del 2004, Universidad Central, Santiago de Chile.

1 Para una visión sintética del pensamiento político de Locke: Ashcraft. 1994. "Locke's political philosophy". En The Cambridge Companion to Locke. Edited by Vere Chappell. Cambridge: Cambridge University Press, pp. 199-225. 
de la obra: las ideas de libertad y consentimiento. En la arquitectura del Segundo Tratado el concepto de libertad es la piedra angular de la teoría moral de la persona humana, sobre la cual descansa el origen del Estado. La libertad se proyecta como causalidad de todos los actos políticos substantivos del hombre bajo la forma de consentimiento. Locke sostiene que el ser humano es naturalmente libre. Y su libertad, a través del consentimiento, es la fuerza moral que anima y da forma concreta e histórica a la sociedad civil o política y al régimen o gobierno. En consecuencia, este texto expone el intento lockeano por establecer la libertad humana como fundamento y origen de la vida política, y, además, la actualización permanente de esa libertad, en el flujo de esa vida, a través del consentimiento.

La pregunta fundamental que preside todo el pensamiento político de Locke puede enunciarse del siguiente modo: si, como sabemos, el hombre es libre por ley de la naturaleza, ¿por qué usa su propia libertad para someterse a la condición de sujeción política? La respuesta a esta pregunta, que brota del Segundo Tratado sobre el gobierno, se ordena en seis etapas. En la primera, se describe la situación originaria del hombre en estado de naturaleza, que se caracteriza por la libertad, la igualdad y la independencia de todos los miembros de la especie humana. La segunda analiza el acto de consentimiento por el cual, según el autor, los hombres abandonan el estado de libertad natural, para integrar la sociedad civil y darse a sí mismos un régimen político. En la tercera, el campo de estudio se desplaza hacia las formas y proyecciones del consentimiento en las dimensiones cruciales de la vida del cuerpo político. La cuarta se ocupa de los derechos que los individuos transfieren para dar vida a la comunidad política y al gobierno. La quinta aborda la cuestión de la naturaleza del poder delegado del gobierno o régimen político. Por último, se trata el tema de la disolución del cuerpo político y del gobierno, puesto que en ese escenario crítico la libertad y el consentimiento se exponen al extremo de sus posibilidades.

\section{ESTADO DE NATURALEZA: LIBERTAD NATURAL Y LA LEY DE LA NATURALEZA 0 DE LA RAZÓN}

La primera idea que enfrenta a Locke con sus antagonistas -partidarios de la doctrina de la sujeción natural del hombre ${ }^{2}$-, afirma que, por el contrario, ellos son libres por naturaleza. $Y$ a efectos de explicar esta condición esencial del ser humano, escenifica su existencia originaria en un "estado de naturaleza". La concepción del estado de naturaleza ha sido un tema extraordinariamente debatido. No entraremos en el detalle de esa controversia acerca de la realidad histórica o puramente abstracta y teórica del estado de naturaleza. Participo plenamente de la tesis de Richard Ashcraft, quien sostiene que el concepto de estado de naturaleza es una "ficción moral", cuya finalidad es dar cuenta de la estructura fundamental del hombre como ser moralmente libre. Y que sólo secundaria e instrumentalmente, como corresponde a un teórico político, Locke apela a datos históricos que confirmarían la existencia de un estado de naturaleza en estadios pre políticos, primitivos o primigenios, de sociedades que posteriormente se organizaron políticamente 3 .

El Primer Tratado del Gobierno de Locke está integralmente dedicado a refutar a Robert Filmer, autor del Patriarca o el Poder Patriarcal de los Reyes, que sustenta como único régimen político legítimo la monarquía de iure divino, fundada en el poder absoluto que Dios habría concedido a Adán y que éste trasmitió a la posteridad del género humano por vía de la primogenitura.

3 Dunn (1969), pp. 96-119. 
La libertad de los individuos en estado de naturaleza, o estado moral original del hombre, consiste en que nacen dotados de la facultad de juzgar y decidir por sí mismos acerca de lo que es necesario y suficiente para su conservación y bienestar, sin estar sujetos a la autoridad de ningún otro hombre, salvo la de Dios ${ }^{4}$. Esta capacidad, igualmente repartida entre todos los miembros del género humano, los hace independientes, o sea, dependientes sólo de sí mismos, exentos de toda sujeción o dominación terrenal ${ }^{5}$.

La independencia de los seres humanos para valerse por sí mismos, en todo lo que concierne a su preservación y bienestar, se funda en el poder para extraer de su propia razón las normas para conducir su vida libremente y hacerse cargo del cuidado de sus semejantes. A las normas que el hombre extrae de su propia razón, Locke las llama indistintamente leyes de la naturaleza o de la razón ${ }^{6}$. Según Locke, todos los hombres, y este es un sello distintivo de la especie humana, disponen de la guía de la ley de la naturaleza para regular y medir sus actos. No tienen sino que acudir a su propia razón, la cual, en su función práctica, siempre les va indicar la norma conductora de su acción. Esta capacidad de adecuación entre la norma emanada de la razón y el caro humano está tratada por Locke en su obra filosófica y moral. También se trata de un asunto debatido. $Y$ aunque tampoco nos extenderemos en este asunto, porque no es pertinente en este ensayo, me atrevo a sugerir el planteamiento que sigue.

Es claro que Locke, en el Segundo Tratado, remite la ley natural a un fundamento teológico. El argumento de Locke parte de la premisa de que el estado natural es gobernado por una ley natural, y esa ley obliga a todos los hombres ${ }^{7}$. Sobre esa premisa, Locke nos advierte que la razón, que coincide con esa ley (and reason, wich is that law), les enseña a cuantos humanos quieran consultarla (teaches all mankind who will but consult it) que, siendo todos iguales e independientes, nadie debe dañar a otro en su vida, salud, libertad o posesiones (life, health, liberty, or possesions $)^{8}$. Enseguida, Locke expone el fundamento teológico de su argumento, que está articulado siguiendo el orden discursivo de las siguientes proposiciones: (1) todos los hombres son creaciones de Dios (Supremo Hacedor). (2) Dios es Supremo Hacedor omnipotente e infinitamente sabio (omnipotent and infinitely wise Maker). (3) Los hombres, como creaturas de Dios, son todos ellos servidores de un único Señor soberano (....all the servants of one sovereigs Master). (4) Los hombres existen en el mundo por su voluntad -y mientras a Él la plazca- y no por la voluntad de algún otro ${ }^{9}$. Ahora bien, si la ley de la naturaleza es la expresión de la voluntad legisladora de Dios y ella es la ley de la razón, el fundamento de la libertad es la voluntad de Dios. Dios hace libres a los seres humanos porque les entrega la facultad de juzgar por sí mismos todo lo concerniente al cuidado de sus bienes esenciales, y, en virtud de la igualdad y la reciprocidad, el cuidado de los bienes esenciales del otro.

La concepción filosófica de la ley natural de Locke no está desarrollada en el Segundo Tratado, sino en los Ensayos sobre la Ley de la Naturaleza, escritos originalmente en latín. Esta obra fue

Locke (1976), II, pp. 4-10.

Locke (1976), VIII, 119, p. 61. El texto dice: "Every man is ...naturally free, and nothing being able to put him into subjection to any earthly power but only his own consent..."

Locke (1976), II, 6-8, pp. 5 y 6.

Locke (1976), II, 6, p. 5.

Locke (1976), II, 5, p. 5.

Locke (1976), II, 6, p. 5. 
publicada póstumamente. Y los textos que contiene son de los años sesenta del siglo, época de la juventud de Locke. La distancia temporal con los Dos Tratados plantea problemas interpretativos, pero hay una cuestión capital en la que no existe contradicción entre la obra temprana y la madura de Locke. Tanto en los Ensayos como en el Segundo Tratado, más que exponer una demostración de la existencia de la ley natural, se la describe como un elemento del orden universal, moral y físico, creado y gobernado por Dios ${ }^{10}$. La existencia de Dios no está en cuestión, simplemente se acepta porque su inexistencia es inaceptable: así lo muestra o evidencia la realidad física del universo y la realidad moral de la vida humana. Es por esta razón que Locke considera el descubrimiento de Dios como lo "más natural de la razón humana"11, pues ella se impone como una suerte de evidencia. Esta visión de Locke es la consecuencia de su postura epistemológica contraria a la posibilidad de demostrar deductivamente la existencia de Dios $^{12}$, como lo hacen Aristóteles y Aquino, por ejemplo. Sobre este supuesto, la ley de la naturaleza se funda absolutamente y sin duda en Dios, pero un Dios cuya naturaleza y existencia no podemos alcanzar a través del saber deductivo. Doy por supuesto que Locke en otros textos se refiere a la existencia de Dios según los contenidos de la revelación, o sea, desde el punto de vista de la fe.

Desde la mirada filosófico-teológica, la ley de la naturaleza puede ser descrita como "un decreto de la voluntad divina, cognoscible por la luz de la razón natural del hombre, que señala aquello que está conforme o disconforme con la naturaleza racional, y que, por lo mismo, se expresa por la formulación de una orden o de una prohibición"13. Este argumento hace equivalente la voluntad divina con la ley de la naturaleza, que, no olvidemos, es la ley de la razón. Ahora bien, eso quiere decir que Dios mismo es el autor de la ley de la naturaleza y no la razón. Pero es la razón, nos dice Locke, la que la hace cognoscible y aplicable a los actos humanos. Esta argumentación es perfectamente coherente con la posición madura de Locke, tal como se expresa en el Segundo Tratado.

En el Ensayo sobre el Entendimiento Humano trata acerca de las reglas morales, las leyes, la ley divina y la ley civil. En ese texto Locke define las relaciones morales de las personas como aquellas en las que hay conformidad o disconformidad entre las "acciones voluntarias de los hombres en relación con una norma a la cual puedan referirlas y de acuerdo con la cual son juzgadas"14. Esta noción la aplica Locke a los distintos tipos de leyes, a las cuales les atribuye la calidad de ser reglas del bien y del mal morales ${ }^{15}$. Por inferencia, es el caso de los actos que se ciñen a la ley de la naturaleza o de la razón. Las leyes de la naturaleza miden y regulan los actos humanos y los adecuan al bien, dándoles un estatuto moral. De este modo, la libertad humana, como dice Locke, no es licencia para hacer lo que se quiere ${ }^{16}$. La ley natural indica que nadie dispone de su propia vida y, consecuentemente, tampoco de la vida del otro ${ }^{17}$. Y justamente para que los individuos no se hagan

10

Locke (1958), I, p. 109. Locke recurre al teólogo anglicano Richard Hooker (1553-1600) como argumento de autoridad para confirmar sus proposiciones. Hooker, Richard: The Works of that learned and judicius divine Mr. Richard Hooker. Oxford: At Clarendon Press, 1888. Vol. I, Of the Laws of the Ecclesiastical Polity, I, II-III, p. 200-212; I, V-VIII, p. 215236.

Locke (1976), I, p. 110.

Locke (1976), I, p. 111.

Locke (1976), I, p. 111.

Locke (1999), libro II, XXVIII, sección 4, p. 335. Ver Ashcraft (1994), p. 906.

Locke (1999), libro II, XXVIII, sección 13, p. 340.

Locke (1976), II, 6, p. 5.

Locke (1976), II, 6, p. 5. 
daño entre sí es que la misma ley de la naturaleza ha puesto en cada cual el cuidado de sí y del otro, para lo cual le concede el derecho a castigar las trasgresiones a sus normas ${ }^{18}$.

Los individuos, en suma, pueden vivir pacíficamente y proteger sus bienes esenciales en estado de naturaleza. La libertad, la igualdad y la independencia de la cual los individuos son portadores y su capacidad para regular su vida gracias al uso práctico de su propia razón, nos interpelan en el momento de explicar por qué querrían integrarse a una sociedad políticamente organizada. Si en estado de naturaleza la ley de la razón ordena y regula relaciones de reciprocidad justas y equitativas, para que nadie tenga más jurisdicción y poder que el otro, ¿por qué querer salir del estado de naturaleza?; ¿por qué abandonar ese estado de "perfecta libertad"? ${ }^{19}$ Según Locke, la razón principal es que los individuos, en estado de naturaleza, están expuestos a la incertidumbre e inseguridad en el cuidado de sí (su vida, libertad y posesiones), que el autor llama genéricamente propiedades ${ }^{20}$, y del otro ${ }^{21}$. En efecto, en estado de naturaleza, cada cual es soberano: "todos son reyes", dice el autor. Esto es, cada cual extrae de su propia razón la ley de la naturaleza, y la aplica a su vida y al cuidado y relaciones con el otro, operando como juez que juzga las trasgresiones a la ley de la naturaleza, y emitiendo sentencias y aplicando penas coercitivas, si es necesario. Uno de los principales derechos que la ley de la naturaleza atribuye a los hombres es, justamente, el poder de castigar al trasgresor de esa ley22. Los hombres, iluminados por la recta razón y ley natural, que es accesible a todos ${ }^{23}$, son inducidos a una vida pacífica, pero el carácter particular de sus juicios legislativos y judiciales, y el ejercicio de su fuerza individual para castigar al trasgresor de la ley natural, son propicios para crear un estado de incertidumbre e inseguridad, el espacio para el error en la deducción y la aplicación de la ley natural, la mala intención y la violación deliberada de la ley natural. Locke advierte que no todos los hombres, "reyes" por igual en el estado de naturaleza, observan estrictamente la equidad y la justicia"24 y pueden torcer la significación y aplicación de la ley natural por interés e ignorancia.

Pero, más allá del error, la ignorancia y las pasiones, la causa más devastadora de la paz del estado de naturaleza es la voluntad preconcebida y deliberada de algunos hombres de suplantar la ley de la naturaleza por el ejercicio de la fuerza injusta e ilegal. En efecto, dice Locke, cuando un individuo, a través de palabras y actos, declara un designio tranquilo y calculado contra la vida de otro hombre, sin pasión ni arrebato, se pone a sí mismo en estado de guerra contra quienes ha

\footnotetext{
18 Locke (1976), II, 7, p.6.

19 Locke (1976), VIII, 87, p.43: "Man being born, as has been proved, with a title of perfect freedom, and an uncontrlled enjoyments of all the rights and privileges of the law of nature equally with any other man or number of men in the World, ..."

20 Locke (1976), VII, 87, p. 43: “- no solo el poder de conservar su propiedad, esto es, su vida, libertad y bienes”, “...not only to preserve his property -that is, his life, liberty, and estate-...". Estate es para Locke equivalente a possesions, goods, etc. Muchas traducciones españolas substituyen estos términos por property, properties, produciendo confusión.

${ }^{21}$ Locke (1976), IX, 123, p. 63. Locke, respondiendo a la pregunta de por qué un hombre querría salir del estado de naturaleza, responde: “... a pesar de disfrutar de tales derechos en el estado de naturaleza, es muy incierto (incertain) en ese estado el disfrute de los mismos, (pues) está expuesto a ser atropellado por otros hombres. Siendo todos reyes como él, cualquier hombre es su igual, y como la mayor parte de los hombres no son observantes estrictos de la equidad y la justicia, el disfrute de la propiedad que les corresponde en este estado está muy desprotegido e inseguro (unsafe and insecure)". Los destacados son míos.

22 Locke (1976), II, 12, p.8.

23 Locke (1976), IX, 124, p. 54. Locke, discutiendo por qué se abandona el estado de naturaleza, dice: "a pesar de que la ley natural es clara e inteligible para todos las creaturas racionales etc."

24 Locke (1976), IX, 123, p. 63.
} 
declarado tal intención ${ }^{25}$. Contra aquellos que adoptan un designio de esta índole, poniéndose en estado de guerra, la ley de la naturaleza establece que predomina la salvaguardia del inocente, agredido por el hostil, y, por lo mismo, la extinción de este último. Locke dice que se aplica la misma razón por la cual matamos al lobo o león que nos ataca. El punto crucial de la argumentación de nuestro autor es la siguiente: un hombre hostil, que se pone en estado de guerra, es alguien que (1) se sitúa fuera del ámbito de la ley común de la razón; (2) adopta como suya la ley de la fuerza y la violencia; (3) y se hace acreedor a ser tratado como fiera ${ }^{26} \mathrm{y}$, por lo mismo, se hace merecedor de la muerte.

En el pensamiento de Locke, el estado de naturaleza no es equivalente al estado de guerra, como en Hobbes. En estado de naturaleza opera la ley natural, que manda y prohíbe, y separa el mal del bien. Por lo tanto, el estado de guerra es un estado al cual se llega deliberadamente, con el designio de afectar la vida de un ser humano. El argumento es extensivo a la libertad y las posesiones. Locke dice que quien se propone poner a otro bajo su dominio absoluto, pretendiendo arrebatarle su libertad, también se pone en estado de guerra ${ }^{27}$. Es razonable pensar que quien manifiesta signos de quitarme mi libertad, también busca disponer de mi vida. Y que quien proyecta hacerse de mis bienes, también puede intentar ponerme bajo su sujeción absoluta, con grave peligro para mi vida.

La incertidumbre y la inseguridad, en suma, hacen precaria la paz del estado de naturaleza. De este modo, los hombres aspiran a abandonarlo para crear una sociedad políticamente organizada. Ahora bien, salir de este estado significa (1) crear un cuerpo político dotado de un poder legislativo común, jueces comunes e imparciales, y una fuerza común que vigorice la aplicación de las leyes y las sentencias ${ }^{28}$, y (2) ingresar a una esfera de certidumbre y seguridad en el disfrute de la vida, la libertad y las posesiones materiales; o sea, de la paz garantizada por la ley positiva ${ }^{29}$, el juez neutral y la fuerza común. Por esta razón, los individuos convienen la fundación de la sociedad civil y el gobierno. Veamos ahora en qué consiste este primer nivel del consentimiento aplicado a la constitución del cuerpo político.

\section{CONTRATO Y CONSENTIMIENTO}

Ya sabemos que, según Locke, solamente en virtud de un acto emanado de su propia libertad un ser humano puede ponerse legítimamente en un estado de sujeción. Ese acto, que se funda en el ejercicio de la voluntad libre, se llama consentimiento (consent). Cada hombre posee la facultad 0 el poder de consentir en imponerse a sí mismo algún tipo de sujeción, siempre y cuando no pierda esa facultad, que es inalienable. Esta es la única fuente de sujeción legítima, es decir, conforme a la ley de la razón. Por lo tanto, cada individuo, en tanto libre e igual, y titular de los derechos que emanan de esta condición natural, está habilitado para establecer sobre sí mismo una sujeción

Locke (1976), III, 16, p. 10.

Locke (1976), III, 18, p. 10.

Locke (1976), III, 17, p. 10.

Locke (1976), IX, 124-126.

Tully (1993), p. 293. Tully expresa en forma clara que la ley civil es ciertamente una ley -como pretende serlo la ley natural- que establece lo bueno y lo justo, pero que extrae su legitimidad de la voluntad del legislador (p. 293). 
política, es decir, una sujeción a un poder político ${ }^{30}$. Pero, para ejercer este poder de consentir en tal sujeción, es necesario que cierto número de individuos también lo ejerzan, y, al hacerlo, constituyan la sociedad civil o política y el régimen político que ellos determinen ${ }^{31}$. Una vez que esto ocurre, o sea, cuando cierto número de individuos ha consentido en crear un cuerpo político bajo un gobierno (one body politic under one government), se incorporan a una sola comunidad y cada cual asume la obligación de someterse a las decisiones de la mayoría ${ }^{32}$.

El poder político es aquel suficiente para asegurar y garantizar el disfrute de la vida, la libertad y las posesiones materiales y el cuidado de la humanidad (mankind), que son los bienes originales y primarios que los individuos buscan conservar al crear la sociedad política33. Y, a la vez, es el poder que se ejerce en el marco de un régimen político, que Locke llama "gobierno" (government), y cuya estructura incluye un poder colectivo de legislar, un poder jurisdiccional común -tercero y neutral- para solucionar los diferendos entre los individuos, y una fuerza común que asegure la vigencia de la ley y las sentencias del juez.

A efectos de esclarecer al máximo los argumentos lockeanos sobre el contrato o pacto político es necesario hacer una revisión analítica del texto que la expone. Intentaré, en consecuencia, descomponer el texto distinguiendo pasos o instancias del argumento de Locke, cuya exposición es extremadamente compacta y sintética. El propósito de este ejercicio es destacar y poner de relieve la función de la libertad y el consentimiento en la estructura del contrato.

El primer paso argumental que da Locke se funda en dos supuestos esenciales. El primero se refiere a la condición del individuo en estado de naturaleza, dotado de iguales facultades racionales que le permiten gobernar su vida orientado por la ley de la naturaleza. El segundo, que se deriva de la inseguridad e incertidumbre del cuidado de sí y del otro, propio del estado de naturaleza, sostiene que los individuos desean abandonarlo para ingresar a un estado de paz y seguridad, en el cual esté garantizada la preservación de sus vidas, libertades y posesiones. Dados estos dos supuestos, el primer paso consiste en describir el acto de "cierto" o "determinado número de individuos" que se separa o resta del estado de naturaleza para formar una sociedad civil $^{34}$. Este acto de segregación es voluntario y, por lo tanto, enteramente libre. Para Locke, como veremos más adelante, es un acto formal que vincula un consentimiento expreso. Incluye abandonar derechos individuales que emanan de la ley natural y asumir obligaciones que limitan la libertad soberana de los individuos en estado de naturaleza. Este abandono, además, es "para siempre" o perpetuo $0^{35}$. El abandono de derechos naturales que hacen los individuos es irreversible, porque ellos se trasladan a otro sujeto, que una vez constituido se transforma en su titular.

En este punto hay que explicar que la sujeción voluntaria, de la cual se habla aquí, es positivamente libertad civil. En efecto, la libertad natural se hace a sí misma libertad civil a través del contrato. Esta metamorfosis da como resultado, en palabras de Locke, una libertad que consiste en no

30

Locke (1976), VIII, 95, p. 49. "Siendo los hombres, como se ha dicho, libres, iguales e independientes por naturaleza, ninguno de ellos puede ser puesto fuera de ese estado ni sujeto al poder de otro sin su propio consentimiento - without his own consent"-.

Locke (1976), VIII, 89, p.45.

Locke (1976), VIII, 87, pp. 49-50.

Locke (1976), I, 3, p. 4.

Locke (1976), VII, 89, p. 45 у p. 49.

Locke (1976), VIII, 121, p. 62. 
estar sometido a otro poder legislativo que aquel establecido por consentimiento de la comunidad política, o sea, que pertenezca al régimen constituido por consentimiento mayoritario; ni al dominio de una voluntad particular; ni a las limitaciones que no provengan de las leyes emanadas del poder legislativo, y que éste haya aprobado en conformidad con su poder delegado, o sea, en el marco del poder fiduciario que ejerce ${ }^{36}$. En otras palabras, la libertad civil se ejerce con la misma facultad humana que la natural, y así como en estado de naturaleza el hombre cuenta con la ley natural, ahora dispone de una regla fija y común, que regula su vida en sociedad. Esta regla debe haber sido aprobada por el poder legislativo legítimo. Esa norma común, al mandar o prohibir, deja abierto un amplio espacio donde la voluntad de cada cual es soberana. De este modo, el concepto de libertad civil, junto con acotar el campo de su ejercicio, veta y reduce la posibilidad de que opere una voluntad "inconstante, insegura, desconocida y arbitraria de otro hombre"37 capaz de dominar y ejercer una sujeción indebida. Digo, entonces, que esta libertad civil está en las antípodas de la sujeción de los súbditos de la monarquía de iure divino que Locke refuta en el Primer Tratado del Gobierno ${ }^{38}$.

El segundo paso argumental es la determinación acerca de aquello que abandonan los individuos al salir del estado de naturaleza, esto es el "poder de ejecutar la ley natural"39. Ya sabemos que la ley natural es clara e inteligible para la los seres humanos humanas, y que ella regula sus actos y su relación con los demás. También sabemos que, según Locke, ella prescribe que estando cada cual al cuidado del otro, en estado de naturaleza todos los individuos, particularmente considerados, son jueces que sentencian y aplican penas o castigos. Todo ello pertenece a la esfera "del poder de ejecutar la ley natural". En consecuencia, aquello que se abandona y transfiere a un nuevo sujeto es justamente este poder.

En un tercer paso argumental Locke denomina o nombra al sujeto sobre el cual recae ese poder, que es la vez un derecho, pues emana de las prescripciones normativas de la ley natural. Este nuevo sujeto se llama "sociedad civil" (civil society), que Locke además nombra con los términos "sociedad política" (political society), "cuerpo político" (body politic), "comunidad política" (commonwealth) o simplemente "comunidad" (community) y también con la palabra "pueblo" (people) $)^{40}$. Hay que destacar que en el capítulo X del Segundo Tratado, que trata sobre las formas de gobierno, y con el propósito de distinguir los conceptos de sociedad civil o comunidad política y forma o régimen de gobierno, define la primera, usando el término commonwealth, como la "comunidad independiente que los antiguos llamaban civitas"41. 0 sea, en lenguaje actual, Estado. No obstante, Locke no usa la palabra State, por lo cual lo uso escasamente en este ensayo. Queda así establecido que la sociedad civil de Locke es el Estado, y que éste es distinto a su propia forma de gobierno o régimen político.

En un cuarto paso argumental se explicita que el acto constitutivo de la sociedad política se realiza cuando "cierto número" de individuos que estaban en estado de naturaleza se asocian entre sí y

Locke (1976), IV, 22, p.13.

Locke (1976), IV, 22, p.13.

Locke (1966).

Locke (1976), VIII, 89, p. 45.

El término pueblo (people) aparece por primera vez en el Segundo Tratado en la sección 89, p. 45.

Locke (1976), X, 133, pp. 66-67. 
forman "un pueblo, un cuerpo político, sometido a un gobierno supremo"42. Asimismo, Locke amplía la incorporación al cuerpo político al caso de aquellos que se suman a un cuerpo político ya establecido ${ }^{43}$.

Podemos decir que en el quinto paso, Locke precisa la naturaleza del acto que une a los individuos en un solo cuerpo político: "una vez que un número cualquiera de hombres, por el consentimiento de cada individuo, crean una comunidad, un cuerpo político, con el poder de actuar como un cuerpo, lo cual se consigue solamente por la voluntad y determinación de la mayoría"44, o sea, del consentimiento mayoritario. La pieza clave de este argumento es la función fundadora de la sociedad civil que Locke le asigna al consentimiento. Y como derivación de este carácter principalísimo del consentimiento, su instalación como fuente o causalidad única y exclusiva de los actos del cuerpo político, a través de la decisión de la mayoría (only by the will and determination of the majority).

El sexto paso argumental establece que a través del contrato, como acto de consentimiento, los individuos "autorizan" a la sociedad civil para legislar y ejecutar lo establecido por las leyes, en conformidad con el bien público. En efecto, por este acto, se "autoriza a la sociedad, o lo que es lo mismo, a su poder legislativo para hacer las leyes en su nombre, según convenga al bien público de la sociedad, y para ejecutarlas siempre que se requiera su propia asistencia"45.

Por último, Locke describe la supremacía del poder legislativo que se constituye junto con la sociedad política o civil, como un juez supremo que por sí o por delegados suyos dirime "todas" las querellas y repara todos los daños que puedan afectar a sus miembros ${ }^{46}$. Si tenemos presente que ese juez es la sociedad civil o política o pueblo, en su instancia más esencial, y que el poder legislativo que se le atribuye es supremo, queda establecido un principio fuerte de soberanía popular.

Los pasos quinto al séptimo requieren una explicación adicional. Entre los autores contractualistas se había desarrollado la teoría del doble pacto. Uno de sus principales representante es Samuel Pufendorf (1632-1694). Este autor, en su obra El Derecho de la Naturaleza y de Gentes toma como punto de partida el estado de naturaleza, tal como lo hace Locke, pero sostiene que antes de la creación de régimen político, los individuos pactan asociarse entre sí (pactum asociationis) para integrarse a una comunidad llamada sociedad civil o pueblo. En una segunda fase, la sociedad civil pacta con un individuo o una asamblea la constitución de un soberano (monárquico, aristocrático o democrático). Pufendorf llama a este último pacto "de sujeción" (pactum subiectionis), porque su efecto es trasladar y alienar el poder soberano desde el pueblo a un individuo o a una asamblea y, por lo mismo, poner a sus miembros en estado de sujeción política absoluta. Pufendorf, entonces, diferencia en la fundación del Estado dos pactos. Por el primero, los hombres dispuestos a abandonar el estado de naturaleza, considerados como una multitudo disoluta, o acumula-

Locke (1976), VII, 89, p. 45.

Locke (1976), VII, 89, p. 45.

Locke (1976), VIII, 96, p. 49.

Locke (1976), VII 89, p. 45. Locke usa el significado amplio de la palabra juez, como aquel que establece las normas y soluciona los conflictos, o sea, que es legislador y juez en el sentido específico del término, como son los jueces gobernantes del Antiguo Testamente, antes del establecimiento de la monarquía. El texto inglés es claro: "And this - el contrato - puts men out of state of nature into that of the commonwealth, by setting up a judge on earth with authority to determine all the controversies and redress the injuries that may happen to any member of the commonwealth, which judge is the legislative, or the magistrate appointed by it". 
ción informe de voluntades particulares, convienen en integrarse a un cuerpo político o pueblo dotado de la voluntad de una persona moral y, en consecuencia, realizar actos propios ${ }^{47}$. El segundo acto contractual consiste en la decisión de darse a sí mismo ésta o aquella forma de gobierno. En efecto, dice Pufendorf, la sociedad civil -"que representa los comienzos y el esquema de un Estado- estando ya constituida, debe enseguida hacer una Ordenanza, por la cual se regule la forma de gobierno, sin la cual no habría medios para adoptar medidas fijas para trabajar continuamente por la seguridad común"48.

Locke llama al acuerdo originario agreement, contract o compact, que son sinónimos de pacto y se refiere a él como "un" solo acto. No obstante, según mi interpretación, su contenido consolida en un solo acto de consentimiento dos acciones a las que Pufendorf les confiere el estatuto de pactos. En efecto, el contrato lockeano, junto con constituir la sociedad política o pueblo, establece el régimen político. Pero mientras la acción constitutiva de la sociedad civil es irrevocable, la decisión mayoritaria que crea el gobierno o régimen político es revocable, porque es una delegación. Así, en un solo acto de consentimiento, los individuos crean el pueblo o cuerpo político y, a la vez, a través de la regla mayoritaria, se le atribuye el poder legislativo a un hombre 0 a una asamblea de hombres. Por esta razón, la fórmula más afortunada que usa Locke es aquella en que los individuos al crear "un cuerpo político" lo hacen, a la vez, "bajo un gobierno" (one body politic under one government ${ }^{49}$ ). De este modo, debe entenderse (1) que el pacto origina la sociedad política y (2) que, a la vez, por consentimiento mayoritario se instaura un régimen político. En general, Locke usa la fórmula ilativa, o sea, que por el pacto se origina la "sociedad civil" y "el gobierno", que a mi juicio es menos clara. Pero, en todo caso, Locke nos entrega suficientes elementos como para distinguir dos realidades analíticamente distintas, que emergen de un solo acto de consentimiento. En Hobbes ocurre algo que es distinto tanto de Locke como de Pufendorf, y es que el covenant o pacto entre los individuos no surte el efecto de crear simultáneamente un pueblo y un Estado o Leviatán. El resultado del covenant hobbesianno es la constitución de una persona pública o representativa, cuyo titular "se denomina soberano, y se dice que tiene poder soberano, y cada uno de los que lo rodea es súbdito suyo"50. 0 sea, el pacto sólo establece al soberano y la sujeción absoluta de cada individuo a su persona representativa. Y la única unidad moral que existe es aquella de este soberano, es decir del Leviatán como persona representativa. Esta comparación entre Locke y los dos teóricos contractualistas mencionados permite establecer las bases para entender estudios posteriores de su pensamiento, especialmente aquellos relacionados con la diferente naturaleza y constitución de la sociedad civil, por una parte, y el gobierno civil, por otra.

47 Pufendorf (1987), libro VII, cap. 2, p. 231. Pufendorf sostiene que mientras "muchas personas físicas no formen juntas una sola Persona Moral", solamente ellas pueden actuar y contraer obligaciones particulares, pues solamente hay individuos. Si no existe esa Persona Moral la suma de los individuos es solamente una multitud. Por lo conato, el acuerdo para constituir un solo cuerpo es el cato por el cual se crea a la sociedad civil.

48 Pufendorf (1987), libro VII, cap. 2, p. 232. En este texto, "Ordenanza" equivale a constitución política.

49 Locke (1976), IX, 124, p. 63

50 Hobbes (1980), II, 17. 


\section{EL CONSENTIMIENTO COMO DECISIÓN MAYORITARIA Y LOS ALCANCES DEL CON- SENTIMIENTO EXPRESO Y TÁCITO}

Conviene revisar un aspecto capital del contrato, el cual Locke aborda en el capítulo VIII del Segundo Tratado sobre el Gobierno, donde el autor retoma los argumentos centrales sobre el contrato, poniendo énfasis en la sujeción política y el consentimiento. El texto se abre con una breve recreación de la condición de los individuos en estado de naturaleza, que por ser igualmente libres e independientes, no pueden ser "arrancados" de su estado de libertad natural a no ser que medie un acto de consentimiento, por el cual podrían aceptar voluntariamente ponerse en estado de sujeción ${ }^{51}$, como ya vimos. Pero el texto, además de esta reformulación del contrato, aporta elementos nuevos, entre los cuales voy a destacar aquel que se refiere a la decisión mayoritaria. Según Locke, la regla mayoritaria es el único procedimiento racional apropiado para que el cuerpo político actúe como un todo. Este concepto está esquemáticamente enunciado en el capítulo VII, sección 89, pero ahora se le da consistencia y desarrollo argumental. La sociedad civil, como cuerpo político, posee voluntad y poder para tomar decisiones. Gracias a la fuerza del consentimiento de la mayoría, los individuos que lo componen ${ }^{52}$ operan con una unidad y un poder análogos al del ser humano individual. Hago la comparación, porque la cuestión de la unidad de esta voluntad es esencial, pues de ella fluye la obligación moral y política que vincula a todos los miembros del cuerpo político a la decisión de la mayoría ${ }^{53}$.

La voluntad colectiva, canalizada por la mayoría, adopta decisiones obligatorias, o sea, que son vinculantes para todos los miembros de la sociedad civil, tal como la voluntad individual, guiada por ley de la razón, fundada en la voluntad divina, obliga a cada persona natural a realizar o evitar ciertos actos. La voluntad de la sociedad civil, para decidir los actos que debe realizar o evitar, dispone de un equivalente de la decisión individual, que es la decisión de la mayoría de sus miembros. Locke despeja la alternativa de la regla de unanimidad, por dos razones: la primera es la imposibilidad fáctica para que todos los miembros del cuerpo político efectivamente se reúnan sin que esté ausente ninguno; la segunda, y esencial, es la inaplicabilidad de la unanimidad, dada la diversidad de opiniones e intereses particulares de los miembros del cuerpo político, y el hecho de que ella le da a un solo voto discrepante un veto absoluto. Este veto tiene como efecto la paralización del cuerpo político, por la cuasi imposibilidad de adoptar decisiones unánimes.

Locke incluye en su argumentación sobre la decisión mayoritaria la naturaleza vinculante de la pertenencia al cuerpo político. Una vez que se ha producido el agreement, por el cual cada individuo se ha separado del estado de naturaleza para "incorporarse" a la sociedad civil, sus miembros se obligan a aceptar las decisiones mayoritarias, como si éstas fuesen una decisión de todos. En caso contrario, no habría contrato y los individuos seguirían actuando según su libertad natural y voluntad particular. 0 sea, si el ingreso a la sociedad civil no obligase a sus miembros, cada individuo se podría comportar como Catón, que iba al teatro sólo para salir de él, dice Locke irónicamente. $Y$ así, el poderoso Leviatán no duraría ni siquiera el día en que nació ${ }^{54}$. Toda la 
sociedad política, sostiene Locke, se mueve en la dirección que le imprime la mayor fuerza ${ }^{55}$, es decir, el consentimiento de la mayoría. En ese movimiento, quedan incluidos necesariamente todos los miembros del cuerpo político. De este modo, la decisión mayoritaria obliga a todos, porque contiene en sí misma, según la ley de naturaleza y de la razón, "el poder de la totalidad"56.

En este apartado en que se ha expuesto la idea del consentimiento mayoritario, es adecuado referirse al consentimiento en términos más generales. Una vez que Locke establece que por el consentimiento los individuos abandonan su libertad natural para integrarse a una sociedad civil, surge la cuestión acerca de qué "se entiende por declaración suficiente del consentimiento de un hombre para someterse a las leyes de un determinado gobierno"57. En su respuesta a esta interrogante, Locke despliega su concepción del ámbito y alcance del consentimiento en su aplicación a la constitución de la sociedad civil y el gobierno.

Locke desarrolla su respuesta sobre la base de la distinción entre consentimiento expreso y tácito ${ }^{58}$. En consecuencia, instala la cuestión en la esfera del significado de ciertos actos y palabras, a través de los cuales se revela o hace manifiesto el consentimiento. En el primer caso -aquel del consentimiento expreso- no hay problemas. Cuando alguien, de un modo formal y expreso, consiente en unirse a un cuerpo político, "se hace miembro perfecto de esa sociedad" y sujeto de su gobierno ${ }^{59}$. Este tipo de consentimiento, por el cual se "significa" un acuerdo actual y se declara una expresa incorporación a una comunidad política (commonwealth), tiene valor perpetuo e irrevocable, y, por lo mismo, obliga a quien la hace a permanecer de modo inalterable en la condición de sujeto de esa comunidad ${ }^{60}$. La formulación de Locke es muy clara, pues precisa que esta condición perpetua de pertenencia y sujeción a una commonwealth es irreversible, no permite el retorno a la libertad del estado de naturaleza, salvo que por una "calamidad", o sea, por una causa externa, la sociedad civil misma se disuelva; o que, por la realización de ciertos actos públicos, alguien deje de ser miembro de la comunidad política ${ }^{61}$. Este aspecto del consentimiento desempeña un papel muy importante en el desarrollo de los argumentos del autor sobre la disolución de la sociedad civil y del gobierno, que se trata más adelante.

El ingreso a la sociedad civil se hace a través de un acto que integra a la persona y todas sus propiedades a la comunidad62. Como ya sabemos, la propiedad de cada individuo incluye su vida, libertades y posesiones o bienes. Respecto de estos últimos, Locke dice que el pacto "anexa también y somete a la comunidad" todos aquellos bienes que ya posee y que podrá adquirir, bajo la cláusula de que no hayan pertenecido ni pertenezcan a otro gobierno ${ }^{63}$. Según Locke, es contradictorio pensar que alguien ingrese a la sociedad política para disfrutar de sus propiedades, protegido por ella, y, a la vez, pretenda dejar fuera de la jurisdicción del gobierno la regulación de

Locke (1976), VIII, 96, p.49.

Locke (1976), VIII, 96, p.49: "The act of the majority passes for the act of the whole, and of course, determine, having by the law of neture and reason the power of the whole".

Locke (1976), VIII, 119, p. 61.

Locke (1976), VIII, 119, p. 61.

Locke (1976), VIII, 119, p. 61.

Locke (1976), VIII, 121, p. 61.

Locke (1976), VIII, 121, p. 61.

Locke (1976), VIII, 120, p. 61.

Locke (1976), VIII, 120, p. 61. 
sus posesiones ${ }^{64}$. De este modo, por el pacto, tanto la persona como sus bienes quedan sometidos a la jurisdicción del gobierno y dominio o soberanía de la comunidad política65. Este punto es un antecedente clave para la debida comprensión del consentimiento tácito66.

El consentimiento tácito, en cambio, es problemático. Cuando hablamos de consentimiento tácito, en el ámbito que nos ocupa, el problema de fondo es saber si hay un acto que signifique, indirecta pero suficientemente, la obligación de sujeción a la comunidad que contrae su autor. Según Locke, ese acto es el ejercicio de dominio sobre tierras o posesiones inmuebles que están en el territorio sobre el cual tiene jurisdicción un gobierno constituido ${ }^{67}$. Una persona que ejerce esa acción acepta por consentimiento tácito someterse y obedecer a las leyes de ese gobierno, aun cuando no haya hecho ninguna expresión formal y expresa de tal sujeción ${ }^{68}$. Esta sujeción durará mientras dure el disfrute de sus posesiones. 0 sea, la sujeción será temporalmente coextensiva con la perduración del disfrute: sea que éste dure toda la vida o una semana ${ }^{69}$. En este caso, entonces, las prescripciones morales y legales de sujeción al gobierno son válidas y vinculantes durante períodos específicos de tiempo ${ }^{70}$. Así, el consentimiento tácito tiene un efecto limitado respecto del expreso, porque su poder se restringe a poner a los individuos bajo la jurisdicción temporal de un gobierno.

El disfrute de la posesión presupone que el agente que la disfruta se somete ex ante a la ley y al gobierno del cual ella emana. Todos los actos que conducen a ese disfrute -0 sea, por herencia, compra, autorización, donación, etc.- sólo son posibles si quienes desean realizarlos aceptan como condición necesaria su conformidad con la autoridad del gobierno a cuya jurisdicción están sometidos los bienes de que se trate ${ }^{71}$.

El consentimiento tácito, comparado con el expreso, es débil. No incorpora en plenitud a la sociedad política, sino sólo al gobierno de ella. Recordemos que el consentimiento expreso hace a quienes lo afirman "miembros perfectos" de una sociedad civil. La imperfección y debilidad anexa al consentimiento tácito se explica porque solamente pone a sus agentes bajo la autoridad de un gobierno, dejando en suspenso su plena incorporación a la sociedad civil. En efecto, Locke argumenta que la sujeción de las personas que por consentimiento tácito adquieren el estatuto de sujetos de un gobierno (tacit consent to the governement) ${ }^{72}$, al cual obedecen, sometiéndose a sus leyes y decisiones, lo pierden en cuanto abandonan el disfrute de sus posesiones. Por lo tanto, si por venta, donación o cualquier otro tipo de transferencia de bienes, la persona extingue el vínculo de sujeción antedicho, queda en completa libertad para irse e incorporarse a otra comunidad política, o bien, para unirse a otros individuos y crear por pacto una nueva

Locke (1976), VIII, 120, p. 62.

Locke (1976), VIII, 119, p. 62.

Wollin (1960). En la página 310, Wollin entrega una interpretación distinta a la mía. Sostiene que Locke postula que el ejercicio del derecho de propiedad involucra el ingreso a la sociedad civil. Leyendo la interpretación de Locke advierto una semejanza con la de Macpherson (1962), ampliamente refutada a fines de los años sesenta del siglo pasado.

Locke (1976), VIII, 119, p.61

Locke (1976), VIII, 119, p. 61.

Locke (1976), VIII, 119, p. 61

Locke (1976), VIII, 121, p. 62, El texto dice literalmente: "the obligation of any one is under, by virtue of such enjoyment, to submit to the government, begins and ende with tne enjoyment".

Locke (1976), VIII, 120, p. 62

Locke (1976), VIII, 121, p. 62. 
commonwealth ${ }^{73}$. Ello, como es claro, deja en evidencia que este individuo retorna al estado de naturaleza. A este caso se refiere Locke cuando explica que se puede dar la excepcional situación de un retorno al estado naturaleza por "calamidad" (conquista) o determinados actos de las personas. La conclusión es que el consentimiento tácito no crea la obligación perpetua e irrevocable de pertenencia a una sociedad políticamente organizada, como acontece con el consentimiento expreso, por lo cual deja abierta el retorno al estado de naturaleza.

Mirado desde el punto de vista de la aceptación "de" y obediencia "a" las leyes, bajo las cuales se disfruta del derecho de propiedad, Locke insiste y deja meridianamente establecido que ello no es una causa de incorporación a la sociedad civil. Dicho de otro modo, la conducta de sumisión y obediencia a las leyes de un gobierno no "convierte a un hombre en miembro de aquella sociedad, en sujeto perpetuo de esa comunidad política" (perpetual subject of that society) ${ }^{74}$. De este modo, Locke cierra el capítulo acerca de la extensión del consentimiento, dejando claramente establecido que éste solamente colma plenamente su capacidad causal cuando se ejerce en forma expresa. Aquí cabe hacer una observación, que a mi juicio pasa inadvertida a los intérpretes de nuestro autor. Éste hace referencia a que el acto de un número indeterminado de individuos de salir del estado de naturaleza e incorporarse a una sociedad políticamente organizada es unánime y no puede ser de otra manera. De este modo podemos decir que el acto constituyente de la sociedad política o civil, que la pone en la esfera de la existencia real, es unánime, y que lo que esa unanimidad, ya transformada en un pueblo o cuerpo o comunidad política (Estado) crea por consentimiento mayoritario, es un poder legislativo y a fortiori un gobierno o régimen político. Con esta observación quiero enfatizar una distinción esencial entre el acto de incorporación, que no puede ser sino unánime, y el acto de investirse a sí mismo el cuerpo político de un régimen o constitución, que es un acto mayoritario. La cuestión es si acaso esta diferencia significa algo. Sostengo que el consentimiento expreso y unánime del primer acto funda la sociedad política de modo perpetuo e irrevocable. Y que en cambio, la decisión mayoritaria que origina la forma regiminis crea un vínculo moral y jurídico temporal, esencialmente revocable, y que esta diferencia tiene sus efectos, como intento demostrar más adelante.

\section{LOS DERECHOS NATURALES QUE LOS INDIVIDUOS LE TRANSFIEREN AL CUERPO POLÍTICO}

El contrato -ya lo sabemos- consiste en abandonar y transferir al cuerpo político el poder necesario y suficiente para que éste cumpla con sus fines ${ }^{75}$. Esto tiene tres significaciones. En primer término significa que los individuos consienten, al abandonar el estado de naturaleza, en someter a la regulación de la comunidad política su libertad natural de gobernarse a sí mismos, o sea, su libertad para actuar a la luz de su propia voluntad independiente en la determinación del cuidado de sí mismos y del otro ${ }^{76}$. Implica, en segundo lugar, que la voluntad legislativa del cuerpo político está autorizada para regular la libertad individual, con lo cual se hace manifiesto que los individuos

Locke (1976), VIII, 121, p. 62.

Locke (1976), VIII, 122, p. 62.

Locke (1976), VIII, 99, p. 50.

Locke (1976), IX, 129, p. 65: "The first power. Viz., of doing whatsorver he thougth fit for the preservation of himself and the rest of mankind, he gives up to be regulated by the laws made by the society". 
substituyen parcialmente su voluntad particular por la decisión de la mayoría, en tanto y en cuanto ello sea necesario para garantizar a cada cual, en forma cierta y segura, el disfrute de su vida, libertad y posesiones. Obviamente, el gobierno de sí mismo queda limitado, porque las leyes necesariamente intentarán armonizarlo y hacerlo compatible con el gobierno de sí de los otros. Pero, al mismo tiempo, cada individuo conserva un extenso campo de autogobierno -como ya vimos al definir la libertad civil-, sin el cual su libertad natural no sería compatible con la sujeción voluntaria. En ese campo, además de la conducción de las cuestiones esenciales de la vida privada y del despliegue y plenitud de sí mismo, del self, Locke incluye lo que llama "liberty of inocent deligths"77, que consiste en la libertad de elegir todo aquello relacionado con el goce de de las cosas agradables de la vida y que forman parte del bienestar del hombre.

Pero la renuncia más importante, después de la de "ejecutar la ley natural", es aquella por la cual cada individuo transfiere totalmente su derecho natural a castigar al trasgresor de la ley de la naturaleza ${ }^{78}$. Se trata de la renuncia al uso de la fuerza justa y legal (conforme a la ley natural) para instituir la fuerza común o colectiva, bajo y al servicio de la ley. Más atrás vimos que cada hombre, en estado de naturaleza, tiene el derecho a castigar a todo trasgresor de la ley natural que atente contra la vida, libertad y posesiones de sí mismo o del otro, aplicándole una pena proporcional al daño inferido a la víctima. Este derecho es correlativo con el de la víctima a la reparación. El titular del derecho a castigar al trasgresor es cada individuo en particular, cualquiera que sea su situación en relación a la violación de la ley natural. 0 sea, tanto si es víctima, como si es espectador o está en conocimiento indirecto de una trasgresión. Ello obliga a que, al hilo del cuidado de sí mismo y del otro, debemos aplicar nuestra fuerza física para ejecutar la sentencia que penaliza al culpable. Pero también significa que, cuando se trata del cuidado del otro, queda al juicio de cada cual realizar o no el acto coercitivo. En cambio, el derecho de reparación está enteramente entregado al juicio de la víctima, porque es inseparable del cuidado de sí mismo.

El derecho de castigo, totalmente alienado a la sociedad civil, queda incorporado al poder político, es decir al poder de la comunidad de hacer las leyes, establecer jueces neutrales y disponer de una fuerza común. De este modo, cuando la ley es violada, es el juez imparcial aquel que en conformidad con la ley emite sentencias y establece penas; y aplica la fuerza común para hacer cumplir la penalidad dictaminada. De este modo, toda sujeción coercitiva es traspasada enteramente al cuerpo político, el cual pasa a monopolizar el uso de la fuerza de los hombres. Este traspaso también está justificado por la reciprocidad debida por el disfrute de la cooperación y la compañía y la protección de la vida, libertad y posesiones que nos brinda el poder de todos ${ }^{79}$.

Locke sostiene que todos los poderes del cuerpo político existen previamente en los individuos en estado de naturaleza. Ellos solamente pueden transferir aquello que poseen, pues "nadie da lo que no tiene". Ahora bien, esos poderes tienen un orden, porque los preside y subordina el poder de juzgar a la luz de la razón natural. 0 sea, esos poderes y libertades se jerarquizan según un orden lexicográfico, en el cual el fundamento del segundo (sentenciar) es el primero (crear la ley); y aquel del tercero (dar vigor a la ley y a la sentencia) tanto el segundo como el primero y así sucesivamente. De igual modo se ordenan las propiedades del ser humano: las posesiones se fundan en la 
libertad y la vida, y la libertad en la vida, que es el primer fundamento de las mismas. Igual ocurre con los poderes que resultan de la constitución del cuerpo político. El primer poder, sobre el cual no hay otro poder, salvo el de Dios y la ley natural, es el de hacer, modificar o abrogar la ley. Para Locke, el poder legislativo es el poder supremo ${ }^{80}$ al cual se subordinan los demás poderes: la judicatura y el ejecutivo. Así, el Estado es un macrocosmos cuyo paradigma es el ser humano que realiza su vida según la ley natural o ley de la razón. El poder legislativo es soberano, supremo y máximo, nos dice Locke, como lo es la facultad de la razón humana en el estado de naturaleza. Ahora bien, la potencia legislativa tiene ese rango, por tres razones: (1) es la fuente de la ley: (2) ha recibido su autoridad delegada del cuerpo político y en consecuencia es su representante; (3) sus decisiones, tomadas por el consentimiento mayoritario de sus miembros, obligan a todos los miembros de la comunidad política ${ }^{81}$. Todos los demás poderes políticos emanan de él y le están subordinados.

El consentimiento de los individuos, al hacer el contrato, por lo tanto, instituye la sociedad civil, y a la vez el gobierno o régimen político, cuya estructura debe ceñirse al orden lexicográfico señalado y a la jerarquización consecuente. El régimen político propio de una "comunidad política bien ordenada" (well ordered commonwalths) ${ }^{82}$, deberá consagrar la supremacía del poder legislativo y ponerlo en manos de una asamblea de personas distintas de aquellas que ejercen el resto de los poderes. La salvaguarda de la vida, la libertad y las posesiones -que justifica la renuncia a la igualdad, la libertad y el poder ejecutivo de que disponen los hombres en estado de naturaleza, y la constitución de la sociedad civil y la estructura del régimen político que se sigue del pactoencuentra su último fundamento en el bien común. Este bien obliga al poder supremo de la sociedad políticamente organizada, es decir, al poder legislativo "a gobernar por leyes fijas y establecidas, promulgadas y conocidas por el pueblo"83. El bien común también obliga al establecimiento de jueces rectos e imparciales, encargados de solucionar los conflictos entre los individuos en concordancia con las leyes; y, en fin, a ejercer la fuerza común sólo para hacer cumplir la ley, ejecutar las sentencias y defender a la comunidad del daño y las injurias que puedan provenir de un enemigo exterior ${ }^{84}$.

Una vez que Locke esboza las formas de régimen político que puede asumir el gobierno de la sociedad civil y establecer que en todos ellos siempre es determinante la radicación del poder soberano supremo, es decir el poder legislativo, se plantea la cuestión de los límites de este poder y su relación funcional con el resto de los poderes. Hay que recordar sucintamente que Locke agrega a los tres poderes ya enunciados el poder federativo, que es la facultad de los gobiernos -ejercida por el poder ejecutivo- para conducir las relaciones exteriores, hacer la guerra y la paz, suscribir tratados y convenciones, designar embajadas y realizar todas las actividades de un Estado en su relación con otros Estados, en el entendido que ellas se hallan en una situación similar a la de los individuos en estado de naturaleza ${ }^{85}$. Locke también dedica un capítulo

Locke (1976), XI, 134, p. 67.

Locke (1976), XI, 134, p. 68.

Locke (1976), XII, 143, p. 73. Una "comunidad política bien ordenada" es aquella en que "el bien del todo es considerado como se debe".

Locke (1976), IX, 131, p. 65.

Locke (1976), IX, 131, p. 66.

Locke (1976), XII, 145-148, pp. 74-75. 
y múltiples referencias a la prerrogativa, es decir, el poder que ejerce el titular del ejecutivo guiado por la prudencia y no directamente por la ley ${ }^{86}$, la cual no puede prever todas las contingencias que debe enfrentar un gobierno. En el desarrollo de estos temas, la cuestión del consentimiento tiene un rol, pero no podemos detenernos en ellos, pues prolongaríamos en exceso y sin necesidad la argumentación central de este ensayo. Pues, en definitiva, una vez que se ha esclarecido el ámbito propio del consentimiento expreso -la constitución perpetua de la sociedad políticamente organizada- queda ahora por despejar la cuestión del ámbito del consentimiento expreso mayoritario, cuyo fin es la adopción de un régimen político.

Hay que tener presente que la perpetuidad es un concepto que proviene de la teoría política y el derecho público medieval, que aplica la perpetuitas de la corporatio romana a la comunidad o cuerpo político. Jean Bodin (1530-1596) es el primero en recurrir al concepto de perpetuidad para concebir y definir la soberanía del Estado como la "potestad absoluta y perpetua" de una comunidad para gobernarse por sí misma con independencia, o sea, sin sujeción a un tercero ${ }^{87}$. Bodin también sustenta la idea de perpetuidad del pueblo ${ }^{88}$, como una realidad distinta del Estado. Locke no está lejos de esta concepción cuando sostiene que los individuos al poner a la sociedad civil o política en existencia lo hacen "para siempre", o sea a perpetuidad. De ahí las enérgicas proposiciones que nos dicen que una vez que los individuos constituyen el cuerpo político nunca más pueden retornar al estado de naturaleza. Lo cual parece fuertemente sustentado en la práctica, pues la tendencia generalizada, como lo demuestra la historia y la experiencia presente, es que los pueblos difícilmente desaparecen, aunque carezcan de un sistema político, y que es rara la amnesia que les hace perder la conciencia de su propia identidad, aun en las condiciones más radicales de dominación. La extrema "calamidad" por la cual esto puede ocurrir es un asunto que se tratará más adelante.

Pero la perpetuidad de la sociedad civil no se extiende a la duración en el tiempo de la forma de gobierno que ella adopte. Como hemos visto, sin explicar su fundamento esencial, se da la posibilidad de una sujeción efímera al gobierno de una sociedad civil, sin ingresar a esta última como "miembro perfecto". En forma puramente descriptiva sabemos cómo ocurre: una vez que se extingue el disfrute de los derechos anexos a la posesión, estos individuos recuperan su libertad natural. 0 sea, acontece algo que no pude ocurrir con aquellos que por consentimiento expreso constituyen a la sociedad civil. La explicación de estas dos modalidades causales, por las cuales en un caso la obligación es perpetua y en el segundo temporal, se encuentra en el capítulo XIII del Segundo Tratado. Analicemos el argumento de Locke con alguna detención.

\section{DELEGACIÓN DE LA SOBERANÍA LEGISLATIVA: EL CONCEPTO DE “TRUST” O FIDEICO- MISO}

Locke sostiene, como ya se ha expuesto, que al constituirse el cuerpo político se instituye eo ipso su facultad legislativa, que opera por medio del consentimiento mayoritario. El cuerpo político, por así decirlo, nace dotado de la facultad de juzgar, deliberar y tomar decisiones como un solo todo. Su 
primer acto consiste en darse a sí mismo una forma regiminis, sin la cual carecería de organización. Así, el cuerpo político queda investido de la forma monárquica, aristocrática o democrática. Ahora bien, la respuesta a la cuestión del estatuto que asume la forma de gobierno no es la misma que aquella que da cuenta del mismo cuerpo político, sociedad civil, pueblo o commonwealth. Y ello aun cuando normalmente ambos están unidos en la realidad. Normalmente, digo, porque si bien es imposible que un régimen político exista sin un cuerpo político o pueblo subyacente, se puede dar la situación de un cuerpo político sin régimen político. Esto conduce a sugerir la anterioridad del cuerpo político que surge del contrato. Y la consiguiente posterioridad del régimen político que emana de la voluntad del cuerpo político. Y sostengo que tal anterioridad y posterioridad no son solamente analíticas, sino temporales: lo primero nos separamos del estado de sociedad civil, enseguida nos instituimos como comunidad política, y tercero nos damos un régimen político, por consentimiento mayoritario. Como es imposible que estos tres actos puedan realizarse instantáneamente, substrayéndose a la sucesión del tiempo, es razonable pensar que se den en forma de proceso.

Sobre los supuestos anteriores, Locke afirma que la comunidad política ostenta como suya la soberanía legislativa, el poder supremo legislativo. Y que, en consecuencia, cuando instituye un régimen político y atribuye el ejercicio del poder legislativo a una "parte" o persona del mismo, lo hace por delegación, o sea, sujeto a la revocación: "es sólo un poder fiduciario para actuar en pos de ciertos fines" 89 . Por lo tanto, "siempre le queda al pueblo el poder supremo de apartar 0 cambiar a los legisladores" ${ }^{\prime 0}$. Ciertamente, este poder supremo no es arbitrario, pues está subordinado a la evaluación de la performance de aquel o aquellos en los cuales se delegó el ejercicio del poder legislativo ${ }^{91}$. Ahora bien, tal evaluación es posible, porque en la delegación no hay un contrato de alienación de la soberanía legislativa, como sostiene Pufendorf, sino sólo la delegación de su ejercicio. De no ser así, el pueblo no conservaría el poder supremo recién mencionado.

La evaluación a la cual me refiero es posible porque el gobierno de la comunidad política solamente dispone de un poder delegado que le ha sido entregado en fideicomiso. Locke, insisto, nos lo dice con claridad: is only a fiduciary power. Sus características principales son las siguientes (1) es un poder subordinado a quien lo delega, que es el cuerpo político o pueblo, al cual le pertenece a perpetuidad y de modo inalienable; (2) es un poder en beneficio de aquellos para los cuales se ejerce y no de quien o quienes lo ejercen; (3) es un poder cuyo fin es la preservación de la comunidad, o sea, de la conservación y disfrute de la vida, libertad y posesiones de todos sus miembros; (4) se supone violado el fin del fideicomiso si la autoridad gubernamental se aparta lisa y llanamente de su fin o si es negligentemente realizado ${ }^{92}$.

El fideicomiso (trust) entregado a un fideicomisario (trustee) debe realizar el fin para el cual fue instituido ${ }^{93}$. La comunidad política vela por el cumplimiento del fideicomiso, afirmada en su dere-

Locke (1976), XIII, 149, p.45:“...is only a fiduciary power to act for certains ends".

Locke (1976), XIII, 149, p.45.

Pitkim (1987), p. 29. Pitkin critica a Locke por atribuirles a todos los regímenes una existencia fundada en un poder fiduciario. Ella afirma que esto solamente ocurre en aquellos regímenes donde se puede ejercer la accountability y satisfacer la demanda de responsiveness de los gobiernos. 0 sea, solamente en las democracias. Pero creo que Pitkin pasa por alto el concepto de Locke de "commonwealth well ordered", que supone que su argumento se aplica principalmente a ella. En todo caso, Locke no es perfectamente claro.

Locke (1976), XIII, 149, p. 75.

93 Simmons (1995), pp. 69-73. Diferencias entre contract y trust. 
cho perpetuo, supremo e inalienable de asegurar su propia preservación ${ }^{94}$. Derecho que le prohíbe renunciar a los medios necesarios para conseguir ese fin, y, por lo mismo, a entregar su poder supremo a una "voluntad absoluta y la soberanía arbitraria de otra persona". Y esta es la razón por la cual dispone de un último recurso para hacer cumplir el fin encomendado al gobierno, que es la revocación del fideicomiso y su atribución a un nuevo fideicomisario y el uso de la fuerza o resistencia civil, si fuera necesario. Obviamente, para Locke, la elección por la comunidad de un sujeto al cual ella delega la realización de su propio fin, su propio bien común, es un acto de confianza. La naturaleza profunda de este acto, según John Dunn, no ha sido suficientemente analizada y prácticamente constituye un tema marginal en la teoría política ${ }^{95}$. No es el caso entrar en esta cuestión, solamente me interesa establecer que para Locke el fundamento del gobierno del cuerpo político tiene su propia especificidad, que es diferente al fundamento contractual del cuerpo político considerado en sí mismo.

Ahora bien, el poder supremo radicado en la comunidad política es siempre suyo, pero mientras la delegación está vigente y operativa en un fideicomisario su estado es latente 0 virtual. De este modo, "el poder del pueblo no puede ejercerse sino cuando el gobierno queda disuelto"96. Tal disolución acontece principalmente cuando el poder superior del régimen político, que es el poder legislativo, resulta afectado por algún mal invalidante, que le impide cumplir con su finalidad. Esto ocurre de distintos modos, según el régimen de que se trate. Locke nos propone varios escenarios.

En primer lugar plantea el escenario de un régimen en el cual el poder legislativo no funciona permanentemente y el poder ejecutivo está en manos de un individuo que tiene además atribuciones legislativas ${ }^{97}$. En este caso, dice Locke, se puede considerar que el titular del poder ejecutivo tiene un poder supremo, pero no en el sentido de ostentar el poder soberano legislativo, sino por disponer del "poder supremo de ejecución" del cual se deriva el poder de todos los magistrados subordinados o inferiores del cuerpo polític ${ }^{98}$; pero también puede decirse que es supremo en el sentido de que no pudiendo legislarse sin su consentimiento, no existe un poder legislativo superior a él mismo ${ }^{99}$. El fraseo de Locke deja claro que supremo y soberano no son dos conceptos que se identifiquen. Si bien este tipo de gobernante es supremo, no es soberano. Y eso se expresa en el juramento de fidelidad que se le rinde (o debe rendírsele), que es un homenaje y declaración de obediencia debida a su función de ejecutor de la ley ${ }^{100}$. La violación de la ley por parte de este gobernante extingue la obligación de obediencia, con lo cual queda establecida su sujeción a algo superior a su persona: la "voluntad pública" (public will) de la sociedad civil ${ }^{101}$. En definitiva, dice Locke, la obediencia le es debida en su calidad de "persona pública investida con la autoridad de la ley". En un texto que tiene ecos hobbesianos, Locke, refiriéndose a esta persona pública, agrega: "debe, entonces, mirársele como la imagen, el fantasma, o la representación de la comunidad política, que se mueve en sus actos por la voluntad de la misma, tal como ha sido declarada

Locke (1976), XIII, 149, p. 76.

Dunn (1988), p. 279.

Locke (1976), XIII, 149, p. 76.

Locke (1976), XIII, 151, p. 76.

Locke (1976), XIII, 151, p. 76.

Locke (1976), XIII, 151, p. 76.

Locke (1976), XIII, 151, p. 76.

Locke (1976), XIII, 151, p. 77. 
en sus leyes, por esta razón no tiene otra voluntad y otro poder que los de la ley ${ }^{102 " . ~ C o n ~ e s t e ~}$ argumento Locke rechaza la tesis de la monarquía absoluta de que el príncipe es legibus solutus, o sea, libre y más allá de la ley. Y así también, establece la plataforma para deponer a este tipo de gobernante, cuando éste abandona la sujeción a la ley y substituye la representación y voluntad de la comunidad política por su propia voluntad particular. Desde el momento en que esto ocurre, ese gobernante se despoja de su poder y autoridad y los sujetos quedan exentos de la obligación de obedecerlo. Por lo tanto, los sujetos trasladan su obligación de sujeción, actual y tácitamente, a la voluntad conjunta de la comunidad política.

Los escenarios siguientes son menos complejos, pues se explican a la luz de la subordinación de los poderes del cuerpo político al poder supremo legislativo. En esta línea, el caso paradigmático es aquel de un régimen en que el titular del poder ejecutivo no tiene participación en el poder legislativo, es obvio que está subordinado "a" y es responsable "ante" este poder ${ }^{103}$. Y que, por lo tanto, el poder legislativo tiene poder para extinguir la delegación que lo inviste como persona pública y alejarlo de sus funciones. El principio de subordinación cumple su función en las distintas circunstancias que imagina Locke, relacionadas ahora con la existencia de un poder legislativo que se reúne por convocatoria del poder ejecutivo; o según períodos y tiempos pre-establecidos por la ley constitucional; o bien si está compuesto por un número plural de individuos o no, o si son elegidos, etc.

El principio de subordinación, que incluye la obligación del poder ejecutivo de ceñirse a la ley y ser responsable ante el poder legislativo, es fuertemente reafirmado por Locke cuando se pone en la hipótesis de que el titular del ejecutivo use la fuerza pública, a su disposición y monopolio, para impedir la reunión y actuación del poder legislativo ${ }^{104}$. Esto equivale a violar el fideicomiso puesto en manos del régimen político, que obviamente incluye el gobierno en conformidad con las leyes ${ }^{105}$. Según Locke, en este caso, el gobernante que impide la acción legislativa viola el fideicomiso y se pone en estado de guerra con el pueblo ${ }^{106}$. En esta situación, el pueblo tiene derecho a restablecer el ejercicio del poder legislativo y "a apartar el obstáculo empleando la fuerza" (derecho de resistencia), tratando a quien usa la fuerza de la comunidad política sin autoridad como corresponde a un agresor.

\section{LA DISOLUCIÓN DE LA SOCIEDAD POLITICA Y EL GOBIERNO Y LA ACCIÓN RESTAURADORA DE LA LIBERTAD Y EL CONSENTIMIENTO}

Los argumentos expuestos sobre el consentimiento propio del contrato y el consentimiento mayoritario por el cual la comunidad política instituye un poder fiduciario del gobierno son suficientes para tratar el tema de la disolución de la sociedad civil y el gobierno. En perfecta concordancia con los supuestos ya establecidos, Locke afirma que la sociedad política, civil o pueblo, constituida por un contrato que cada cual realiza con los demás, usualmente y casi exclusivamente (usual, and almost only way) se disuelve por la acción de conquista de una fuerza extranjera que la domina

Locke (1976), XIII, 151, p. 76.

Locke (1976), XIII, 152, p. 77.

Locke (1976), XIII, 155, p. 78.

Locke (1976), XIII, 155, p. 78.

Locke (1976), XIII, 155, p. 78. 
y subyuga ${ }^{107}$. La conquista -calamidad venida desde afuera- impide que el cuerpo político actúe libre e independientemente, procurando por sí mismo su propia preservación, y, por lo tanto, destruye el cimiento de su unidad ${ }^{108}$. Destruida la unidad del cuerpo político, los individuos retornan a su libertad e independencia naturales. Y así, cada cual vuelve a asumir el cuidado de sí y del otro que prescribe la ley de la naturaleza. Para estos individuos se abre la expectativa de reunirse para convenir el establecimiento de una nueva comunidad política o bien incorporarse a una ya existente, como ya sabemos. Locke agrega algo que es patente: la destrucción de la comunidad política o Estado conlleva necesariamente la desaparición de su gobierno. Locke hace un símil para ilustrar la imposibilidad de que desaparecida la comunidad sobreviva el régimen político: "es imposible que una casa conserve su estructura una vez que el huracán ha dispersado y arrastrado los materiales de que estaba construida o un terremoto la ha reducido a escombros"109.

Esta es la "calamidad" a la cual se refería Locke más atrás. Pero, hay que enfatizar que esta causa de disolución de la sociedad política es casi la única. El autor no divisa otras. La razón es que la separación de los individuos del estado de naturaleza y su incorporación en un cuerpo político es de suyo irreversible, tiene un carácter perpetuo e irrevocable que normalmente sólo puede ser destruido por un agente exterior. En cambio, los gobiernos, a causa de la naturaleza del consentimiento que los funda, son más vulnerables a su extinción, porque pueden ser destruidos desde el interior mismo de la comunidad política. Y este hecho, más que el de la desaparición de una sociedad política, es el que parece repetirse con mayor recurrencia en la historia occidental.

Los gobiernos se extinguen por distintas razones. La primera, y más importante para Locke, es aquella causada por la alteración del poder legislativo ${ }^{110}$. Alterar la naturaleza del poder legislativo es afectar bienes esenciales de la sociedad políticamente organizada. Locke describe dos efectos devastadores que resultan de los actos contra el poder legislativo. En primer término, se pone en peligro la paz de la comunidad política, pues el poder legislativo es el supremo juez arbitral de todos los conflictos de sus miembros ${ }^{111}$. En segundo lugar, se erosiona la unidad misma de la comunidad política, porque el poder legislativo es el principio de animación o alma que mantiene "vivo y bien constituido" al cuerpo político ${ }^{112}$. Recordemos que el poder legislativo es el poder soberano de la comunidad política y que a través de su función legislativa regula y ordena la vida del cuerpo político como un todo.

En consecuencia, a partir de las premisas enunciadas, Locke establece un principio normativo de conducta política: si el poder legislativo es afectado, aquellos que legislan en su lugar, o sea, sin autorización de la comunidad política, no deben ser obedecidos y el pueblo puede deshacerse de ellos y proceder a crear un nuevo poder legislativo ${ }^{113}$. Necesariamente este principio se amplía hacia la legitimidad de la resistencia a la fuerza de aquellos que pretendan imponer su voluntad al pueblo. 
En esta situación de extrema crisis, como es la disolución del poder soberano de la sociedad civil "bien ordenada", hay usurpación por terceros del poder delegado y fiduciario que la comunidad política había depositado en sus representantes. De este modo, violado el fideicomiso (trust), desaparece la autoridad del fideicomisario (trustee). Quienes no han recibido ninguna delegación o ésta les ha sido revocada, no son los intérpretes de la voluntad pública, ni personas públicas ni representantes ${ }^{114}, y$, por lo mismo, frente a ellos, los individuos están en libertad para expulsarlos, $y$, en el marco de la comunidad política, establecer un nuevo poder legislativo. En definitiva, como ya se ha reiterado, la comunidad política es juez de la conducta del fideicomisario (trustee), y, como tal, puede retirarle su confianza en virtud de la violación del fideicomiso (trust) puesto en sus manos. En esta circunstancia, además del poder de crear un nuevo gobierno, la sociedad política tiene el derecho a usar la fuerza para alcanzar sus fines.

La responsabilidad del aquel 0 aquellos que ocasionan la paralización e inactividad del poder legislativa es difícil de establecer. Un modo de delimitar esa responsabilidad es inscribiéndola en el contexto de cada régimen político, pues la posibilidad real de usurpar las funciones del poder legislativo está en gran medida condicionada a su estructura de poder. En una monarquía, el príncipe está en una posición privilegiada, pues dispone de todos los recursos de la fuerza y el influjo (1) para sustituir la voluntad del poder legislativo por la suya; (2) impedir que el poder legislativo se reúna en las fechas que corresponda y que actúe libremente ${ }^{115}$, poniendo una barrera material infranqueable para que realice su fin: (3) alterar la composición del poder legislativo sin el consentimiento del pueblo, y, por lo mismo, corrompiendo el sistema representativo: y, (4) en fin, por sí o con el concurso de terceros, transferir la soberanía legislativa a una potencia extranjera. En todos estos casos, la responsabilidad recae sobre el monarca, que dispone de la fuerza pública, el tesoro y los funcionarios del gobierno. En consecuencia, es él quien se hace acreedor de la desobediencia y la resistencia civil ${ }^{116}$.

Locke no trata el asunto en el marco de otras formas de gobierno, porque considera que en ellas es extremadamente difícil que se provoque la paralización del poder legislativo. Existe la posibilidad de una sublevación del pueblo y la conspiración de una minoría (que puede ser una parte del mismo poder legislativo), pero siempre estas causas son menos importantes que la acción de la autoridad unipersonal del poder ejecutivo que conspira y opera contra el poder legislativo.

La segunda causa principal por la cual se disuelve el gobierno es aquella que consiste en el abandono por el poder supremo de ejecutar las leyes, o sea el abandono del poder ejecutivo del cumplimiento de sus funciones ${ }^{117}$. Si el poder ejecutivo no aplica las leyes existentes, precipita la sociedad política a la anarquía y a la disolución del mismo gobierno. La judicatura entra en colapso, porque se suspende la solución de los conflictos a la luz de la ley, ya que ésta deja de estar vigente. En este estado de anomia, tampoco se puede aplicar la fuerza con justicia, pues ella queda reducida a una fuerza nuda.

Tanto la paralización del poder legislativo como el abandono del poder ejecutivo de aplicar la ley dejan en libertad al pueblo para proveer por sí mismo a su conservación, mediante la creación de un nuevo poder legislativo, un nuevo poder ejecutivo, o ambos a la vez. Es decir, en libertad para darse a sí

114 Locke (1976), XIX, 212, p. 107.

115 Según Locke, poder legislativo, como órgano político, es la reunión de un número determinado de personas que tienen libertad de discusión, sin la cual no podrían deliberar y tomas decisiones legislativas.

116 Locke (1976), XIX, 214-217, pp. 107-108. 
mismo un nuevo régimen político. En este punto, Locke concluye que en ningún caso la sociedad civil, o, sea, el pueblo, puede perder el "derecho innato y primordial" e inalienable de conservarse a sí misma. Es desde ese derecho que se establecen las libertades de los miembros de la comunidad política para darse a sí mismo aquel gobierno que mejor garantice sus vidas, libertades y posesiones.

Pero Locke nos habla de otra causa de disolución de los gobiernos: cuando el poder legislativo 0 el monarca actúan en forma contraria al fideicomiso (trust), o sea, violando el fin que la sociedad civil les ha encomendado y para cuya realización les ha delegado poderes que son suyos. El poder legislativo, como fideicomisario (trustee), actúa en violación del fideicomiso (trust) ${ }^{118}$ si invade las propiedades de los individuos y se hace dueño arbitrario de la vida, libertades y posesiones del pueblo. 0 sea, cuando el poder legislativo actúa en el sentido contrario de la causa que movió a los individuos a abandonar el estado de naturaleza: conservar, en la seguridad y con la certidumbre que confieren las leyes positivas fijas y el poder común, su vida, libertades y bienes. $Y$ al actuar de ese modo, también corrompen o destruyen a la índole del poder que los individuos crean al constituir al cuerpo político y darse un gobierno. En efecto, las leyes del régimen político deben asegurar que el poder en sí mismo sea siempre limitado, y que la autoridad o dominio de cada parte y de cada miembro de la sociedad civil sea siempre moderado ${ }^{119}$. Por estas razones, cuando el legislador invade la propiedad de las personas y se constituye a sí mismo como un poder ilimitado e inmoderado, se pone en estado de guerra contra el pueblo, con los costos anexos a esta agresión ${ }^{120}$. Este mismo argumento es válido para el caso en que el agresor es el poder ejecutivo ${ }^{121}$, cuyo titular tiene una amplia gama de alternativas para violentar o evadir las obligaciones que derivan del fideicomiso que lo atan al pueblo, pues con sus recursos no solamente puede actuar contra el poder legislativo, sino también contra la voluntad del pueblo.

La cuestión de la disolución de cuerpo político y del gobierno nos conduce a la conclusión final de este ensayo. A través del tratamiento de este tema se confirma la coherencia y articulación del discurso de Locke sobre el consentimiento. La libertad se expresa a través del consentimiento. Del consentimiento expreso y formal del contrato fluye la sociedad política. La naturaleza de ese consentimiento adopta la forma de poder constituyente. 0 sea, del poder de los hombres para fundar sociedades políticamente organizadas dotadas de la facultad soberana de gobernarse a sí mismas. Y el consentimiento mayoritario, anexo al contrato e indisolublemente unido a él, es el acto por el cual se delega ejercicio de la soberanía suprema -el poder legislativo- en un individuo o en una asamblea y se instituye un régimen político. Extrapolando a un lenguaje no lockeano, se puede decir que la soberanía popular, sostenida por nuestro autor, es de origen, mientras que el ejercicio de la soberanía es solamente de habilitación por autorización ${ }^{122}$. En una sociedad civil "bien ordenada", el consentimiento mayoritario va a animar continuamente su vida política, porque va a operar como la regla para tomar todas las decisiones públicas: atribuir la representación, aprobar las leyes y vigilar y rescatar, si fuere necesario, el trust puesto en manos de un régimen político. 


\section{REFERENCIAS}

Ashcraft, Richard. 1994. "Locke's political philosophy". En The Cambridge Companion to Locke, editado por Vere Chappell.

Cambridge: Cambridge University Press, 199-225.

Bodin, Jean. 1977. Les Six Livres de la République (1533). Scientia Verlag AAlen.

Dunn, John. 1969. The Political Thought of John Locke. Cambridge, London, New Cork, New Rochelle, Melbourne, Sidney: Cambridge University Press.

Dunn, John. 1988. "The concept of 'trust' in the politics of John Locke". En Philosophy in History, editado por Ricard Rorty, J.B. Schneewind y Quentin Skinner. New York, Port Chester, Melbourne, Sydney: Cambridge University Press.

Goyard-Fabre, Simone. 1986. John Locke et la Raison raisonnable. Paris: Librairie Philosophique J. Vrin. Hobbes, Thomas. 1980. Leviatán. México: Edición Fondo de Cultura Económica.

Hooker, Richard. 1888. The Works of that learned and judicius divine Mr. Richard Hooker. Oxford: At Clarendon Press.

Locke, John. 1976. The Second Treatise of Government. Oxford: Blackwell and Basil.

Locke, John. 1966. Primer Tratado del Gobierno. Madrid: Instituto de Estudios Políticos.

Locke, John. 1958. Essays on the Law of Nature (edición de W. von Leyden). Oxford: Clarendon Press.

Locke, John. 1999. Ensayo sobre el Entendimiento Humano. México: Fondo de Cultura Económica.

Macpherson, Crawford Brough. 1962. The Political Theory of Possessive Liberalism. Oxford, New York, Toronto, Melbourne: Oxford University Press.

Pitkin, Hanna Fenichel. 1987. The Concept of Representation. Berkeley, Los Angeles, London: University of California Press. Pufendorf, Samuel. 1987. Le Droit de Natuure et des Gens (edición de Bâle, 1732). Caen: Centre de Philosophie Politique et Juridique, Université de Caen.

Simmons, A. John. 1995. On the Edge of Anarchy. Princeton, New Jersey: Princeton University Press.

Tully, James. 1993. Approach to Political Philosophy: Locke in Contexts. Cambridge: Cambridge University Press. Wolin, Sheldon. 1960. Politics and Vision. Boston: Little, Brown and Company.

Óscar Godoy Arcaya es Ph.D. en Filosofía, Universidad Complutense de Madrid. Profesor Titular de Teoría Política del Instituto de Ciencia Política de la Pontificia Universidad Católica de Chile. Miembro de Número de la Academia de Ciencias Sociales, Políticas y Morales del Instituto de Chile e integrante del Consejo Directivo del Centro de Estudios Públicos.

(E-mail: ogodoy@puc.cl) 